\title{
SOBRE EL SIGNIFICADO DE MOYEIKH EN LOS COMENTARIOS SOBRE MÚSICA DE FILODEMO ${ }^{1}$
}

\author{
Adrian Castillo* \\ Recebido em: 16/11/2020 \\ Aprovado em: 01/12/2020
}

RESUMEN: El presente artículo explora la discusión en torno al concepto de mousiké conservada en los Comentarios sobre música de Filodemo de Gadara, principalmente la relación entre poesía y música tal como la conciben Filodemo y sus adversarios estoicos. Esa misma relación se explora también en los textos de Platón, señalando los vínculos entre la defensa del concepto de mousiké como un arte poético-musical y el proyecto de una educación a través de la música. Finalmente, se sugiere la existencia de una correspondance, hasta ahora no reconocida, entre la larga cita de las Leyes con la que concluye la primera parte de los Comentarios y la sección de la "réplica" en la que Filodemo aboga por un concepto de mousiké como un arte independiente de la poesía.

PALABRAS-CLAVE: Filodemo de Gadara; estoicismo; Platón; música; poesía.

\section{ON THE MEANING OF MOY IIKH IN PHILODEMUS' COMMENTARIES ON MUSIC}

\begin{abstract}
The aim of this paper is to examine the discussion around the concept of mousike preserved in the treatise On music by Philodemus of Gadara, mostly the relationship between music and poetry as conceived by Philodemus and his stoic opponents. The same relation is then explored in the texts of Plato, signaling the connections between the concept of mousike as a musicopoetic art and the project of an education-throughmusic. Finally, the existence of a non yet acknowledged correspondance is
\end{abstract}

\footnotetext{
${ }^{1}$ Una versión preliminar de este texto fue presentada en la "XX Jornada de História Antiga da UFPEL: melodias visuais, poesias musicais: antiguidades sonoras", celebrada del 3 al 7 de junio de 2019 en la Universidad Federal de Pelotas.
} 
proposed, between the long quotation from Plato's Laws with which the first part of the book nearly ends, and that section of the "critical" part in which Philodemus advocates for a conception of mousike as an art entirely distinct from poetry.

KEYWORDS: Philodemus of Gadara; stoicism; Plato; music; poetry.

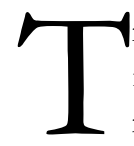

ras unos años en el jardín epicúreo de Atenas, Filodemo de Gadara se estableció finalmente en la bahía de Nápoles alrededor del año 75 a.C. Más o menos por esa mismaépoca, redactóunos Comentarios sobre música, cuyos cuatro volúmenes quedaron sepultados bajo las cenizas del Vesubio en el 79 d.C. Recuperados en el siglo XVIII entre los fragmentos papiráceos de la "biblioteca filosófica" de Herculano, ${ }^{2}$ con el tiempo hicieron célebre a su autor debido a la prematura modernidad de sus ideas, visto que este distinguía nítidamente, quizá por primera vez, entre música y poesía, restringiendo aquella a la materia sonora de ritmos y melodías:

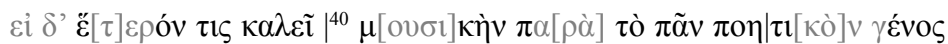

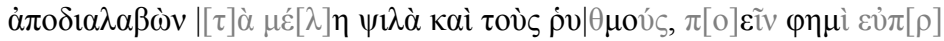
$\varepsilon \pi \tilde{\omega} \zeta$. (YПM 143, 39-43 Del.)

Si alguien llama 'música' a una cosa distinta de todo el género poético, manteniendo aparte de él las melodías desnudas y los ritmos, digo que lo hace apropiadamente.

Melodías “desnudas” ( $\psi \imath \imath \alpha \alpha$ ) es la forma usual de referirse a las melodías sin palabras,

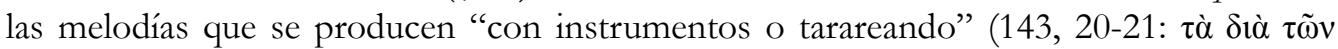

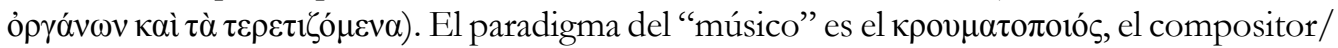
ejecutante de aires instrumentales:

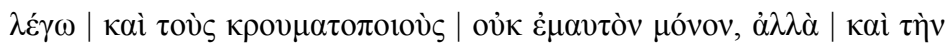

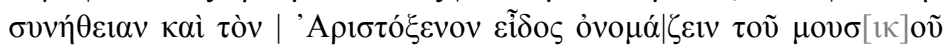
(YПМ 143, 12-17)

Digo también que no solo yo, sino también el uso común y $\left[{ }^{[c e} \mathrm{el}\right.$ propio] Aristóxeno, llamamos al compositor de aires instrumentales una especie del músico. ${ }^{3}$

\footnotetext{
${ }^{2}$ Sobre Filodemo y la "biblioteca filosófica" de Herculano, véase Dorandi, 1995; Sider, 2005 y más recientemente, Longo Auricchio et al., 2020.

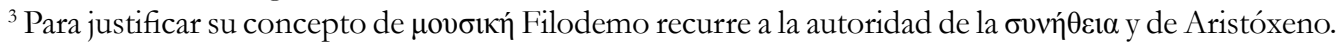
El recurso al "uso común" encaja bien con la filosofía epicúrea, según la cual se debe atender primeramente al sentido común de las palabras (v. Epicuro, Carta a Herodoto $37 \mathrm{ss}$.). El recurso a Aristóxeno es, evidentemente, un recurso a la autoridad. Sin embargo, ninguna de estas afirmaciones es en sí misma evidente y ambas, por distintas razones, son díficiles de evaluar; la tarea, en todo caso, excede estas páginas.
} 


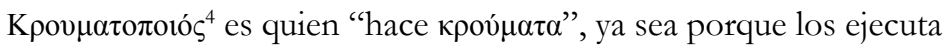
o porque los compone. En sentido musical, el término крой $\mu \alpha$

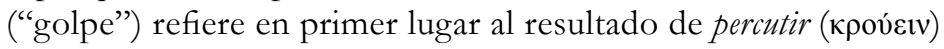
con la púa ( $\pi \lambda \varepsilon \dot{\kappa} \kappa \rho o v)$ las cuerdas de una lira o cítara, en oposición

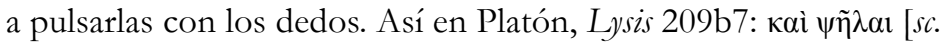

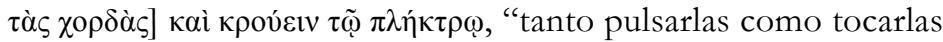
con la púa”. Un escolio al pasaje anota que $\psi \tilde{\eta} \lambda \alpha$ significa "tocar

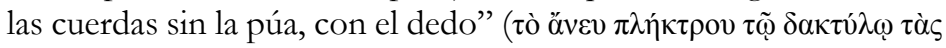

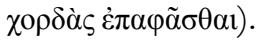

En estos contextos parecería que кроú $\mu \alpha \tau \alpha$ refiere específicamente a los golpes de la púa; ${ }^{5}$ en otros, se aplica por metonimia a las notas producidas, como en el apócrifo Minos (317d8e1), donde se habla de distribuir o asignar крov́ $\mu \alpha \tau \alpha$ adecuados a las melodías. ${ }^{6}$ A menudo, empero, equivalen a melodías instrumentales. Los $\kappa \rho o v ́ \mu \alpha \tau \alpha$ de la cítara pueden oponerse a los $\alpha \hat{\lambda} \lambda \eta ́ \mu \alpha \tau \alpha$, las melodías del aulós. ${ }^{7}$ Pausanias cuenta $(3,17,5)$ que los Lacedemonios no

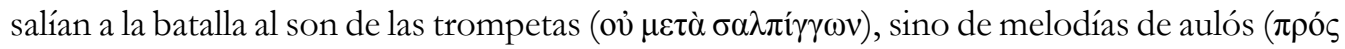

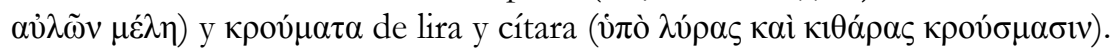

La terminología se extendió desde la lira hacia el resto de los instrumentos, en particular al aulós. Considérese, por ejemplo, un pasaje donde los $\kappa \rho o v ́ \mu \alpha \tau \alpha$ son equivalentes a los vó $\mu$ or musicales, cuando en el tratado Sobre la música del pseudo-Plutarco se dice que

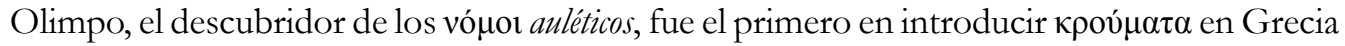
(De musica 1132e10-f1). ${ }^{8}$

En cualquier caso, los $\kappa \rho o v ́ \mu \alpha \tau \alpha$ son siempre melodías instrumentales. En un pasaje

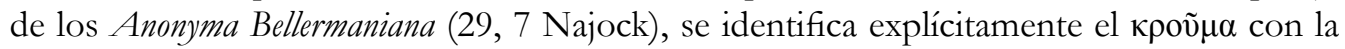

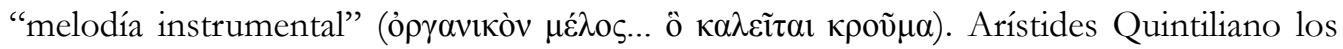

\footnotetext{
${ }^{4} \mathrm{El}$ término está poco atestiguado. Los principales testimonios están vinculados al artista Doríon

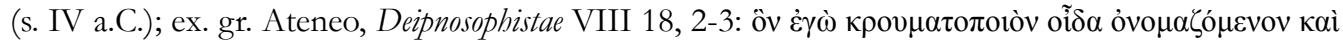

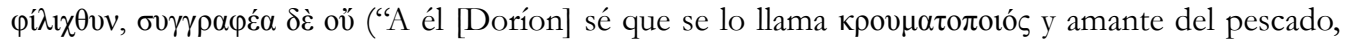

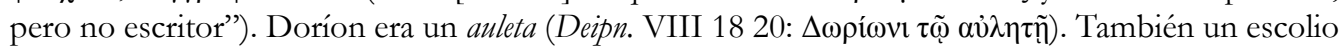

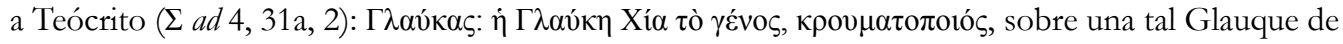
Quíos, quizá una aulétride.

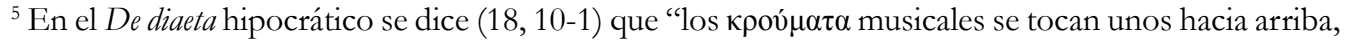

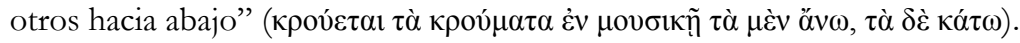

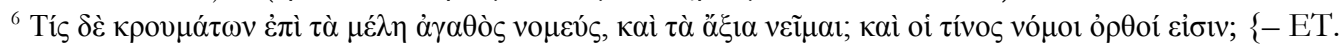

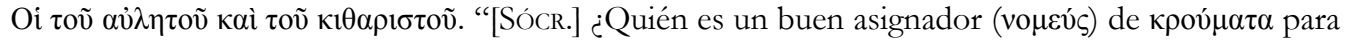
cada melodía, capaz de asignar (veĩual) los que son apropiados? ¿Y las asignaciones (vó son aquí las correctas? [Disc.] -Las del auleta y el citarista."

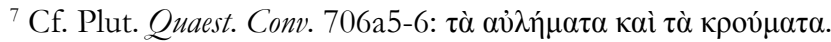

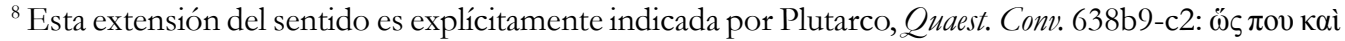

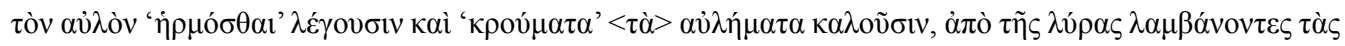

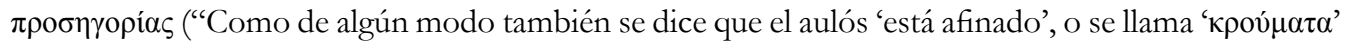
a los aires auléticos, tomando estas denominaciones de la lira”).
} 


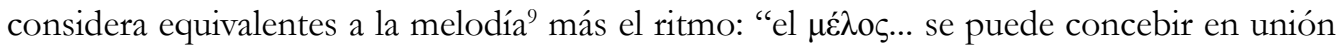

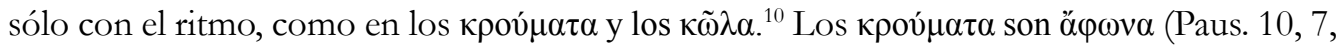
7). ${ }^{11}$ En este sentido, se oponen a las melodías vocales y a las canciones, ${ }^{12}$ y no representan el aspecto "musical" de una melodía vocal, sino que son, como decimos, melodías propiamente instrumentales. ${ }^{13}$

Ciertamente, se puede tararear un крой $\mu \alpha$ con la voz, como dice Filodemo y se decía también en un fragmento de los $\Delta \tilde{\eta} \mu \mathrm{o}$ de Éupolis: "tarareando este tipo de кроó $\mu \alpha \tau \alpha$ " (frg.

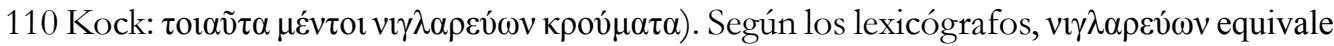
a $\tau \varepsilon \rho \varepsilon \tau i \zeta \zeta v .{ }^{14}$ Es interesante aquí la glosa de Hesiquio ( $\tau$ 518): "tarareos: falsas canciones. Los

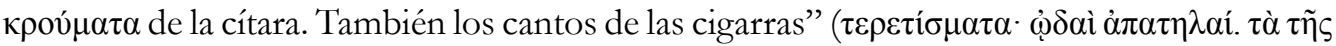

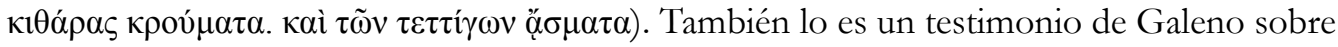

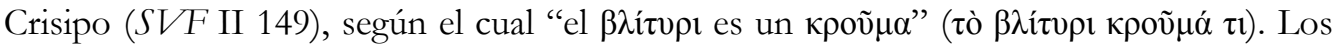
estoicos usaban la onomatopeya $\beta \lambda i$ itupı para representar el sonido de una cuerda, tomado

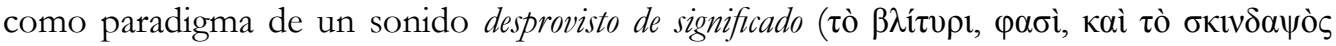

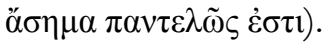

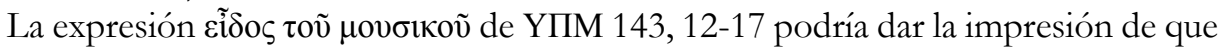
Filodemo solo se interesó por hacer algo que suena extraño e innecesario para nosotros:

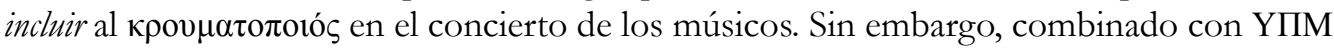
$143,39-43$, que insta a mantener separadas de las palabras las melodías y los ritmos, se hace evidente que su intención era hacer algo que nos es familiar, pero que no lo era tanto para

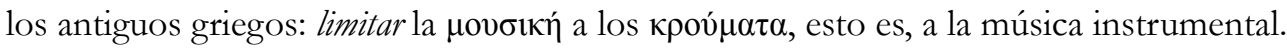

Esto tiene una consecuencia importante para los compositores de canciones, como Simónides y Píndaro, que resultan ser artistas híbridos, suma de poetas y músicos:

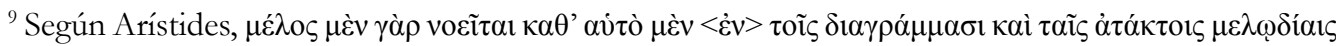
"el $\mu \dot{\varepsilon} \lambda$ o $\varsigma$ se concibe por sí mismo en los diagramas y en las melodías desestructuradas" (I 13, 22-3 W.-I.). El " $\mu \varepsilon ́ \lambda o \zeta$ en sí mismo” es, pues, la melodía sin el ritmo, es decir, las notas. Según Barker, la referencia a los $\delta 1 \alpha \gamma \rho \alpha ́ \mu \mu \alpha \tau \alpha$ implica que Arístides se refiere a la representación de una escala musical (Barker, 1989, p. 435, n. 159).

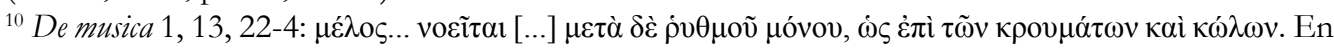
este tipo de contextos $\kappa \tilde{\omega} \lambda \alpha$ no puede tener el significado métrico usual, sino que ha de referirse a

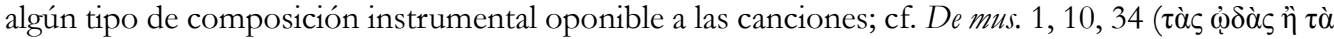

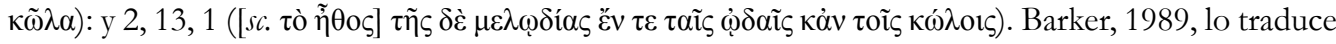
ya como interludes, ya como instrumental pieces.

${ }^{11}$ Para la octava edición de los juegos Píticos se instituyeron certámenes de "citaristas, los que se

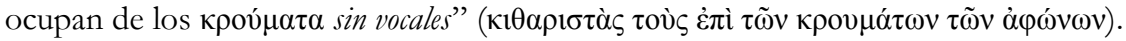

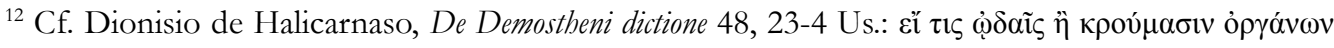

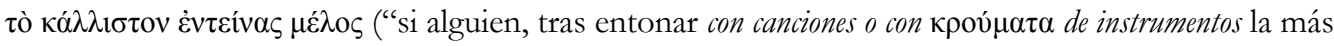
bella melodía...”).

${ }^{13}$ En la notación de Arístides Quintiliano (De mus. 1, 11, 36-8) se indica en dos series separadas "los

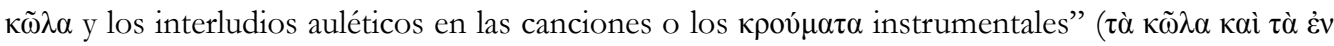

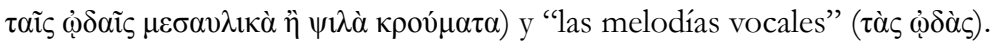

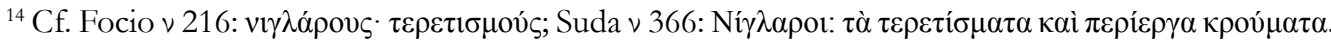




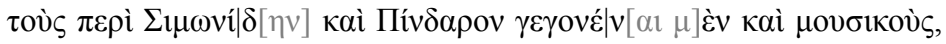

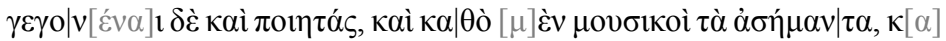

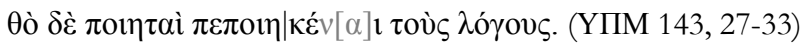

Los [ ${ }^{s c}$ compositores] al estilo de Simónides o Píndaro tanto han sido músicos como han sido poetas, y en tanto que músicos han compuesto cosas desprovistas de significado, pero en tanto que poetas han creado $\lambda$ ó

Las composiciones líricas deben ser analizadas, por lo tanto, desde dos puntos de

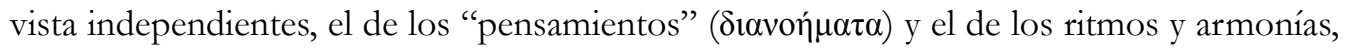
distinguiendo sistemáticamente estos elementos y evaluando por separado el efecto de cada uno. "En tanto que músicos - dice - sólo enseñan lo que circunda a las palabras" (YПM 143,

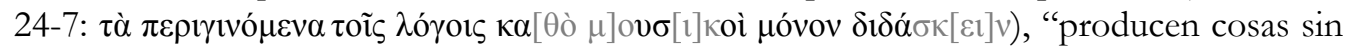

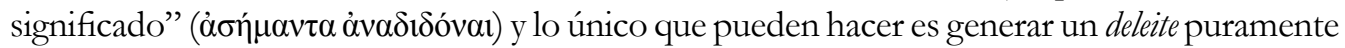

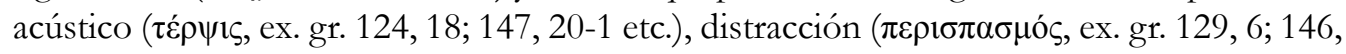
39) o entretenimiento ( $\psi v \chi \alpha \gamma \omega \gamma i ́ \alpha$, ex. gr. 125, 19; 131, 29), una suerte de cosquilla al oído, semejante al placer, natural pero innecesario que nos produce un postre o un perfume (cf. $92,1-5)$. En tanto que poetas, "producen discursos" ( $\lambda$ ó $\gamma o v \varsigma \grave{\alpha} v \alpha \delta \imath \delta \tilde{\omega} \sigma \mathrm{l})$, y en tal medida pueden beneficiar, aunque poco en relación al beneficio que ofrece la filosofía. ${ }^{15}$

\section{II}

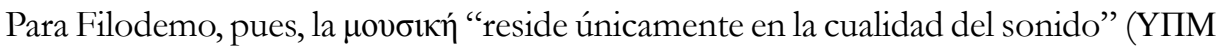

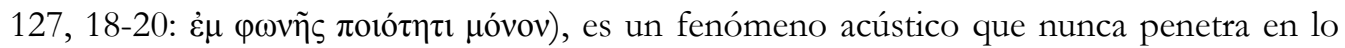
profundo del alma, ${ }^{16}$ pues se agota antes en "sonidos que ponen en movimiento únicamente

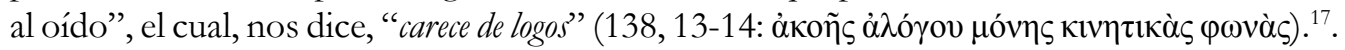

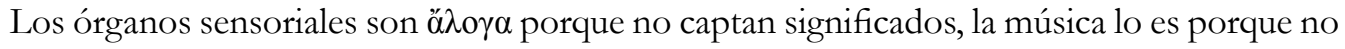
los transmite, y en este sentido, Filodemo dice también que las producciones de los músicos son $\dot{\alpha} \sigma \eta ́ \mu \alpha \nu \tau \alpha$ (YПM 140, 30-1). ${ }^{18}$

\footnotetext{
${ }^{15}$ Este punto de vista lo encontramos expresado también en Sexto Empírico, Adv. Math. VI 28.

${ }^{16}$ Cf. YПМ 116, 30-38, donde este es presentado como el punto de vista naturalista sobre la música: "los más naturalistas (oi $\delta \dot{\varepsilon} \varphi v \sigma \imath \mid \kappa \omega ́ \tau \varepsilon \rho[0] \imath$ ) exhortan a recolectar de cada una de ellas [i.e. de las armonías]

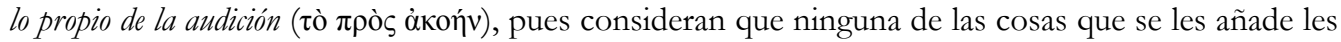
es propia de acuerdo con su naturaleza. La situación es análoga también en el caso de los ritmos y las composiciones melódicas" (itálicas mías).

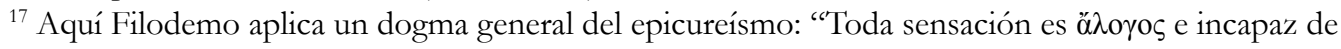

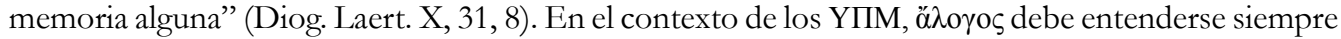
en sentido lingüistico, como "incapaz de captar o expresar pensamientos", no en sentido matemático. Esta interpretación traería problemas serios y no es necesario atribuírselo a Filodemo.

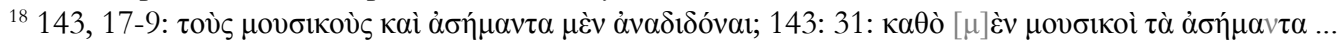
$\pi \varepsilon \pi \mathrm{o} \eta \kappa \varepsilon \dot{\varepsilon} v[\alpha] \mathbf{l}$.
} 
De aquí deduce a su vez la incapacidad de la música para representar las diversas disposiciones del alma y rechaza la idea tradicional de que la música contiene $\mu \mu \eta \dot{\sigma} \sigma \varepsilon ı \varsigma$ de las pasiones y los caracteres del alma (v. YПM 117, 23-42). En general, Filodemo sostiene que la música es incapaz de afectar el espíritu en modo alguno que sea relevante para la felicidad. Esto se debe a que, para Filodemo, tanto las pasiones como las virtudes son disposiciones fundamental, cuando no exclusivamente, intelectuales. ${ }^{19}$ Sirva como ejemplo la siguiente crítica de la eficacia de la música para generar una "virtud erótica", esto es, una disposición para

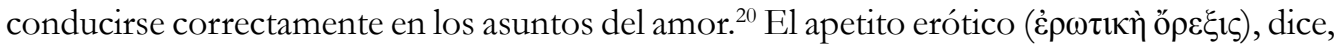
es en ante todo una enfermedad que hay que curar, y es ridículo

creer que las melodías contribuyen a la conducta correcta en el amor, siendo que residen únicamente en la cualidad del sonido, y que el alivio y la calma residen en el razonamiento que enseña lo vano, dañino e insatisfactorio del amor, hasta llegar a una tregua. (YПM $127,10-25)$

La pasión erótica, para Filodemo, es básicamente la creencia misma o bien el resultado de creer que la posesión de lo amado es una fuente natural de placer. Creencia equivocada, pues se trata más bien, sugiere, de una fuente de dolor. Enseñar racional, discursivamente esta verdad es la única cura eficaz contra el mal de amor, y esto es algo que los sonidos sin significado jamás podrán hacer. A lo sumo, lograrán distraernos del mal, aliviarlo, pero curarlo nunca podrán.

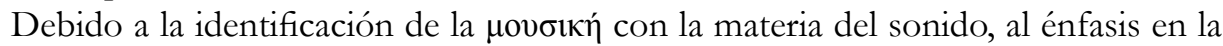
música instrumental y a la crítica de la mímesis musical, se ha señalado a Filodemo como el primer exponente no solo del concepto moderno de música, sino del formalismo musical. Esto es solo una verdad a medias. ${ }^{21} \mathrm{El}$ objetivo de Filodemo no es proponer una teoría

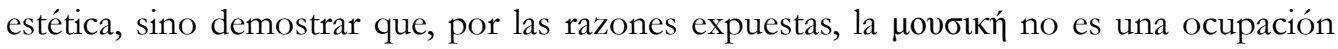

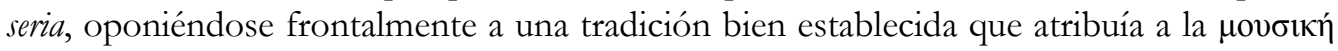
un valor ético y educativo supremo.

\footnotetext{
${ }^{19}$ Sobre este tema, que no pretendo desarrollar aquí, puede verse Annas (1994) y Tsouna (2007).

${ }^{20}$ Para el caso de las virtudes, considérese el siguiente pasaje sobre la justicia (YПM 138 12-21): "no es

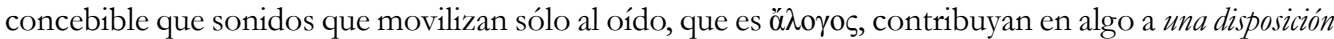

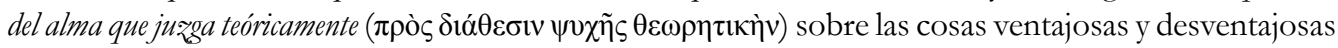
para nuestra mutua convivencia política" (itálicas mías).

${ }^{21}$ Esta cuestión excede el presente artículo. Me limito a señalar que Filodemo coincide sin duda con la tesis negativa del formalismo, a saber, que la música no representa nada externo a sí misma. Pero es muy discutible que sostenga nada parecido a la tesis positiva, según la cual el contenido de la música "es su propia forma", ni con el "dinamismo musical" defendido por Hanslick, que no es sino una teoría positiva sobre el significado de la música, según la cual ella puede representar los aspectos dinámicos, móviles de la realidad. La respuesta adecuada a este problema ya la dio Bowman (1998, p. 136).
} 


\section{III}

Los Comentarios sobre música son en esencia un texto de polémica filosófica, de los primeros en su género, en el cual se ataca la idea de que "la música es útil para muchos aspectos de la vida y que el gusto por su arte nos dispone apropiadamente para la mayoría de las virtudes, o mejor dicho, incluso para todas", ${ }^{22}$ una tesis atribuida a Damón de Oa, que

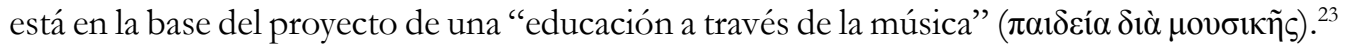

Como otros textos polémicos de Filodemo, se articula en dos partes bien diferenciadas: un epítome o resumen de opiniones adversarias (cols. 1- ca. col. 54), seguido de una réplica (ca. cols. 54-152), que retoma en líneas generales el orden expositivo del epítome. La réplica incluye a menudo ecos, en forma de citas o paráfrasis más o menos extensas del resumen, reconocidos muchos ya por Kemke, a partir de los cuales Delattre ha elaborado una tabla de correspondencias. ${ }^{24}$

Resumen y réplica guardan entre sí una relación semejante a la existente entre la

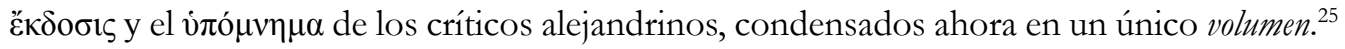
En ocasiones, Filodemo se refiere a su propia obra como bypomnémata. ${ }^{26}$ Por esto -y para distinguirla de los muchos otros tratados De musica de que tenemos noticia, o cuya existencia conjeturamos- sigo la práctica, iniciada por Daniel Delattre, de referirme a esta obra como

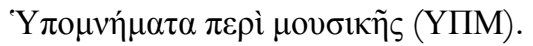

En cuanto a los adversarios de Filodemo, existen dos posiciones sobre su identidad, que dependen de cómo se entienda la relación entre los fragmentos papiráceos herculanenses, en particular la relación entre el PHerc. 1497 (cuya subscriptio secunda lista cuatro libros "sobre la música", siendo este, según la subscriptio primera, el cuarto y último) y el resto de los fragmentos adscritos a los YПM. En la primera edición crítica, la de Ioannes Kemke (Teubner, 1884), estos fragmentos se distribuyen entre los primeros tres libros, según la hipótesis de que el libro I contenía un resumen de las posiciones sobre la $\mu$ оvбıкń defendidas por las principales escuelas filosóficas griegas -ordenadas cronológicamente: platónicos, peripatéticos, estoicos-, al tiempo que los libros II-IV ofrecían sendas réplicas a cada una de ellas.

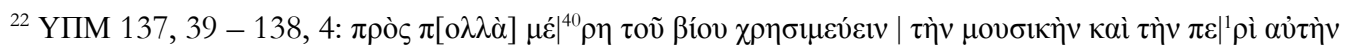

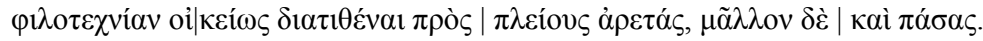

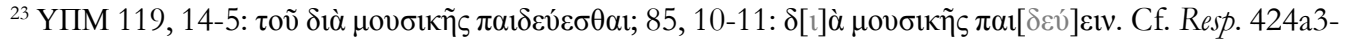

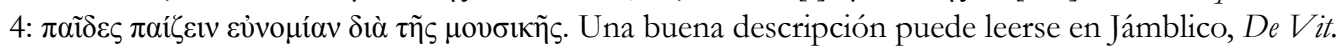

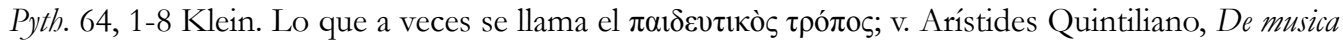

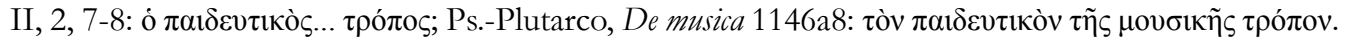
Este es el tema de todo el segundo libro de Arístides Quintiliano (vid. II, 1, 2).

${ }^{24}$ Delattre, 2007, p. CLXXXIII-CCI.

${ }^{25}$ Sobre el vं ${ }^{\prime} \mu v \eta \mu \alpha$ alejandrino, v. Montana (2015). Esta estructura Filodemo pudo haberla tomado de Zenón de Sidón, véase Filodemo, Ad Contubernales 10, 9-15 Angeli.

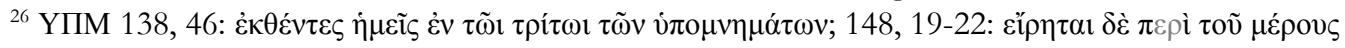

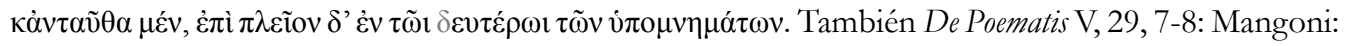

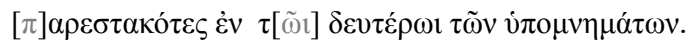


Este modelo editorial persistió hasta la edición de Annemarie J. Neubecker (Bibliópolis, 1986). Pero todo cambió radicalmente tras el trabajo colosal de Daniel Delattre, que en su edición del texto (Belles Lettres, 2007) asignó todos los fragmentos conservados al libro IV, de cuyo volumen incluso logró construir una maqueta completa. ${ }^{27}$ Junto a esta nueva reconstrucción, propuso la tesis, aceptada generalmente por toda la crítica, de que toda la réplica de YПM IV tiene un único o, al menos, principal adversario: el estoico Diógenes de Babilonia. $^{28}$

\section{IV}

Sin embargo, en la sección de los YПM que nos concierne (140, 14 ss.), esto es, la sección en que se discute el concepto de $\mu$ оvбıќ, Filodemo no se dirige directamente a figuras de la tradición filosófica, sino que trae a escena a unos adversarios contemporáneos, anónimos -posiblemente estoicos, seguidores de Diógenes, ${ }^{29}$ adversarios que han lanzado

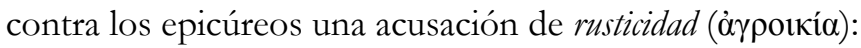

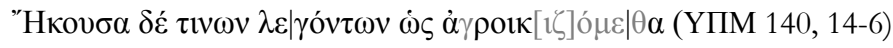

He sabido de algunos que dicen que somos rústicos...

Esta acusación suele considerarse el motivo principal para la redacción de los YПM. A fin de cuentas, el proyecto filosófico de Filodemo consistió en revitalizar el epicureísmo volviendo al estudio de los textos fundacionales (los de Epicuro, Metrodoro) y reformulando la relación del epicureísmo con la $\pi \alpha \iota \delta \varepsilon i ́ \alpha$, desarrollando las doctrinas del Jardín en ámbitos hasta el momento dominados por los estoicos. ${ }^{30}$ Así Filodemo comenzó a "constituir poco a poco una reflexión estética propia del Jardín". A juzgar por ciertos pasajes de los YПM, la polémica previa a la redacción de los YПM debió haberse desarrollado oralmente durante cierto tiempo, en cuyo lapso los adversarios tuvieron también la oportunidad de formular sus propias críticas y Filodemo, a su vez, la de enfrentarlas. ${ }^{31}$

${ }^{27}$ Delattre, 2007, p. CCI-CCXXXIII.

${ }^{28}$ v. Delattre, 2007, p. 1-5. Diógenes de Babilonia, nacido en Seleucia del Tigris hacia 240 a.C., llegó a Atenas a finales del siglo. Siguió allí las lecciones de Crisipo de Solos y Zenón de Tarso, sucediendo a este último como escolarca del Pórtico alrededor del 170. Tuvo entre sus alumnos a Carnéades, quien sería luego uno de los críticos más agudos del estoicismo. Junto a él y a Critolao, un viejo Diógenes tomó parte en la célebre embajada de filósofos que los atenienses enviaron a Roma en 155 a.C. Este suceso lo señala, quizá, como uno de los introductores del estoicismo en el mundo latino, y es verosímil que los estoicos latinos de la generación siguiente tuviesen a Diógenes entre sus principales referentes. ${ }^{29}$ Ferrario, 2011, p. 76: "Gli avversari diretti sono stoici: anzitutto Diogene di Babilonia attivo nel II

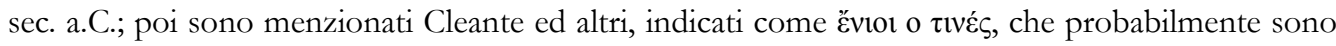
contemporanei di Filodemo, persone ancora vive, non nominate per opportunità."

${ }^{30}$ Delattre, 1996, p. 89. Este proyecto lo había iniciado ya Zenón de Sidón, escolarca del Jardín durante la estadía de Filodemo en Atenas.

${ }^{31}$ Filodemo da a entender que las discusiones eran frecuentes (YПM 84, 5-6), y declara haber tenido numerosas ocasiones para hacerse entender ante quienes le prestaran atención (YПM 144, 3-6). 
Los YПM serían una suerte de reporte final de esta confrontación, que habría derivado en última instancia en una problematización del concepto mismo de $\mu$ оvбıќ́. Dice Filodemo:

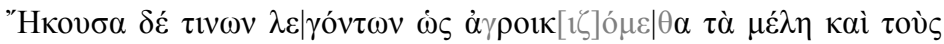

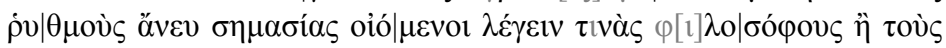

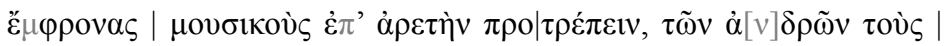

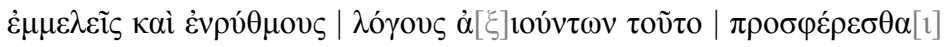
(YПМ 140, 14-24)

He sabido de algunos que dicen que somos rústicos por creer que ciertos filósofos y músicos con juicio dicen que las melodías y los ritmos desprovistos de significado nos ponen en el camino de la virtud, siendo que estos hombres siempre han considerado que son las palabras con melodía y ritmo las que producen esto.

El reproche es doble. Por un lado, decían, los filósofos nunca dijeron que los ritmos y las melodías condujeran a la virtud, sino las palabras con melodía y ritmo. Esto no implica, necesariamente, que creyeran que las melodías y ritmos "desnudos" carecieran de significado,

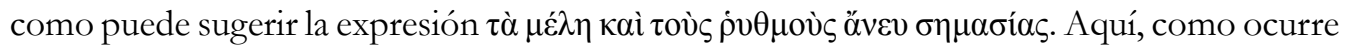
en otras ocasiones, hay que cuidarse de la formulación de Filodemo, viciada como suele estar por sus propias concepciones. Probablemente sus adversarios estoicos creían que las melodías y los ritmos tenían un cierto "significado"-sin duda Diógenes lo creía-, pero aun así sostuvieron, por alguna razón, ${ }^{32}$ que su capacidad paideútica solo es efectiva cuando van asociadas a las palabras.

A este primer reproche le sigue inmediatamente otro, dirigido a la aplicación del

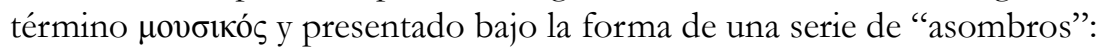

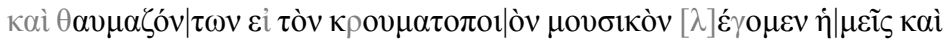

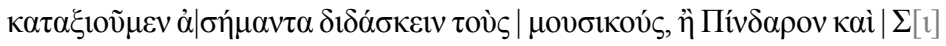

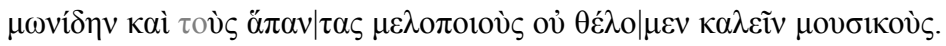
(YПМ 140, 27-35)

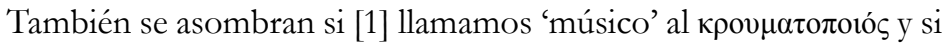
[2] consideramos que los músicos enseñan cosas sin significado, o si [3] no queremos llamar 'músicos' a Píndaro, a Simónides y a todos los compositores líricos.

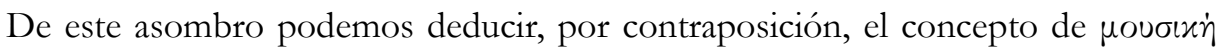
sostenido por los adversarios de Filodemo. Voy a dejar de lado aquí, nueva y deliberadamente, las consideraciones sobre el significado de la música y sobre su naturaleza mimética. A juzgar

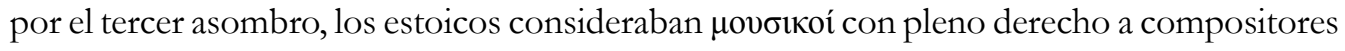
como Píndaro y Simónides. Esto podría inducirnos a pensar, otra vez, que su concepto

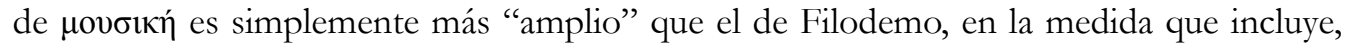

\footnotetext{
${ }^{32}$ Sobre este tema, que excede los límites de estas líneas, puede consultarse Barker (2001).
} 
además de la música instrumental, también la música acompañada de poesía. Pero es claro que, como evidencia la primera sorpresa, los adversarios se resistían a llamar " $\mu$ ovøıкó $\zeta$ " al крочнатолоเós. Este hecho, notable, hace manifiesto que, según estos adversarios, la música

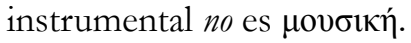

Si conectamos el reproche con los asombros, resulta manifiesto también que la consideración pedagógica (a saber, que solo las palabras con melodía y ritmo conducen a la virtud), es la motivación principal para persistir en el concepto "tradicional", arcaico-clásico,

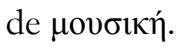

\section{V}

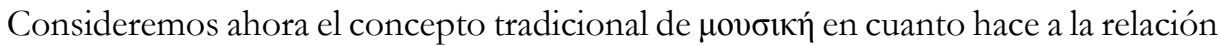
que en él se establece entre la poesía y la música. Me limitaré a tomar como ejemplo la obra de Platón, por comodidad y porque quisiera en última instancia iluminar la presencia, hacia el final del resumen de los ҮПМ, de una larga cita de las Leyes en la que se introduce la noción de "música de las Musas", noción que considero íntimamente conectada con la polémica que nos ocupa.

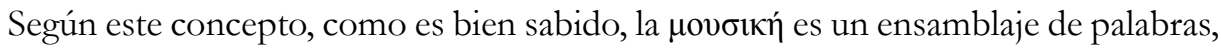
ritmos, armonías y movimientos corporales..$^{33}$ En la República Platón la consideró en primer lugar qua uno de los dos ingredientes, junto a la gimnástica, de la $\pi \alpha 1 \delta \varepsilon i ́ \alpha$ tradicional griega

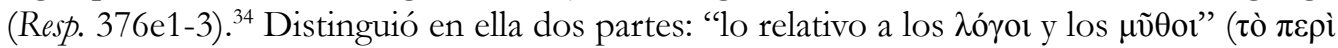

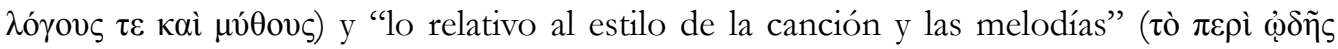

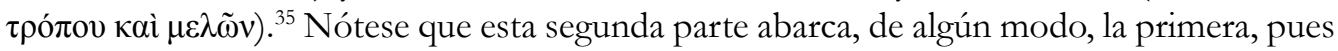
el $\mu \dot{\lambda} \lambda \mathrm{o}$, que se identifica con las melodías vocales y las canciones, se dice que "se compone

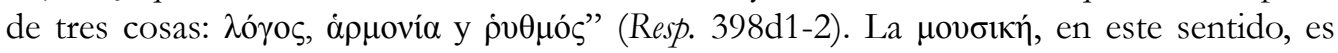
equivalente a $\pi$ oínбıs. ${ }^{36}$

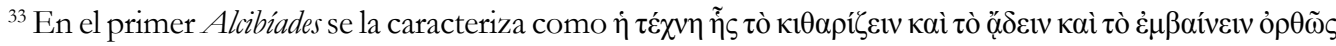
(Alc. I 108c7-8). Cf. ex. gr. Murray; Wilson, 2004, p. 1: "In its commonest form, mousike represented for the Greeks a seamless complex of instrumental music, poetic word, and co-ordinated physical movement"; Rocconi, 2015, p. 82: "the Greek culture of mousike included song, poetry, and physical movement, all integrated within an all-embracing event which served to define culture, ethnicity, and gender, and was a core element of many religious and social rituals".

${ }^{34}$ Cf. Critón 50d7-e5. Esta misma idea se encuentra al principio del resumen de los YПM (esp. col. 8, 3-12).

${ }^{35}$ Resp. 398b6-c2; cf. 522a2-b1.

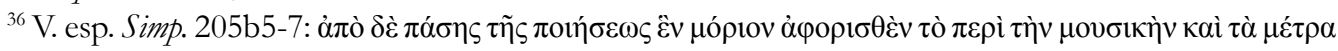

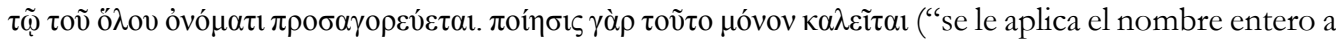

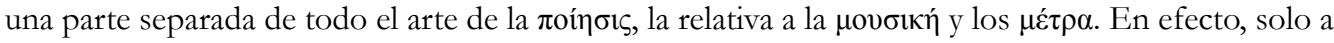

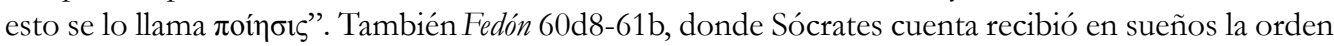

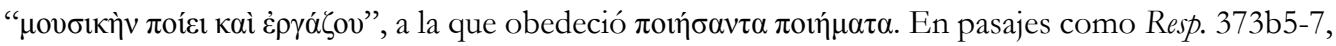
la $\mu$ ovбıкท́ se concibe como una empresa colectiva que involucra una gran variedad de personajes que

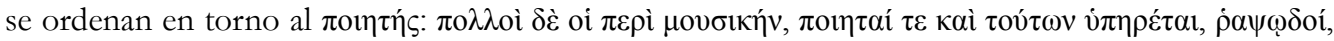

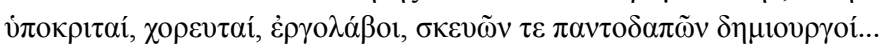


Otro ejemplo elocuente nos lo ofrecen las Leyes. Allí el concepto central es el de

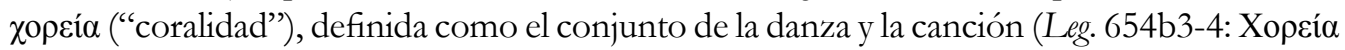

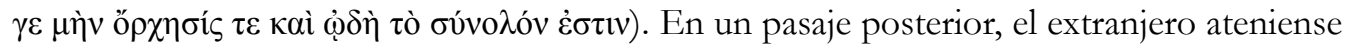
vuelve sobre estas dos mitades de la $\chi 0 \rho \varepsilon i ́ \alpha$, señalando que una mitad corresponde a "lo

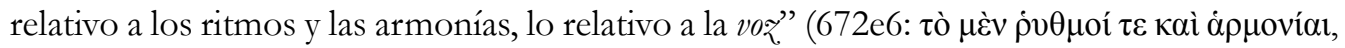

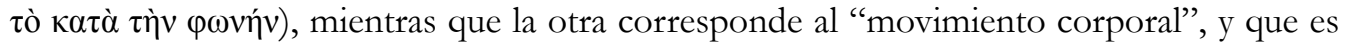

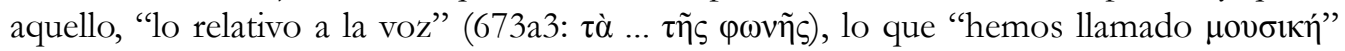

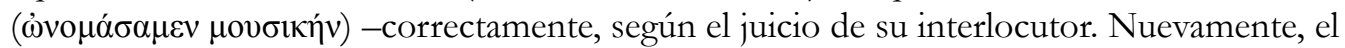
concepto de $\mu$ ovбıкń gira en torno al arte de la canción ${ }^{37}$ y de la música vocal. Al contrario de lo que observamos en Filodemo, cuando se habla de armonía y ritmo se habla siempre de la melodía vocal, no del acompañamiento instrumental. ${ }^{38}$ La música instrumental es considerada subsidiariamente, como un añadido que debe doblar la línea de la voz.

Este concepto, amén de amplio, es inclusivo en el sentido de que, si bien orbita en torno a la voz, incluye ocasionalmente también composiciones que emplean solo algunos de los elementos que venimos mencionado. Así puede considerarse parte de la $\mu$ ovбıń tanto

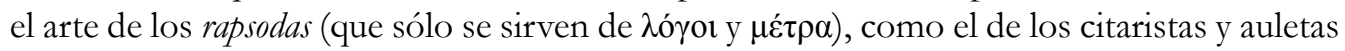
(que sólo usan $\dot{0} \theta \mu$ oí y $\alpha \rho \mu$ ovíal). ${ }^{39}$

Respecto al arte de estos últimos, consideremos ahora la presencia en Platón de un

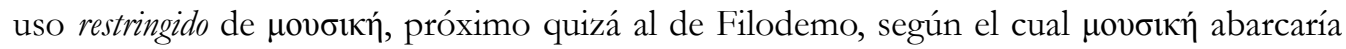
únicamente los ritmos y las $\alpha \rho \mu o v i ́ \alpha .{ }^{40}$ Muchos de los ejemplos son ambiguos, en la medida en que es perfectamente posible que se trate más bien de un punto de vista restringido desde el cual se aborda una realidad poético-musical única, la canción. Considérese por ejemplo el

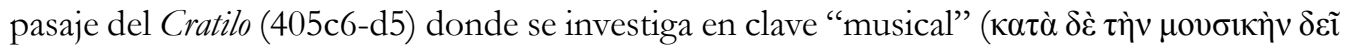
vं moverse "junto con los polos celestes" (los detalles no importan aquî), de donde se obtiene una referencia final a la $\dot{\alpha} \rho \mu o v i ́ \alpha$, tanto musical como astral. El nombre significa, pues, que

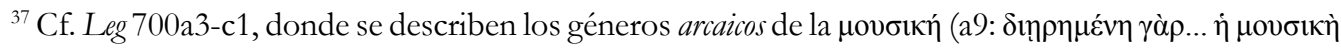

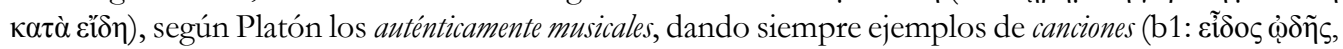

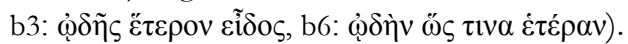

${ }^{38}$ Cf. Rocconi, 2015, p. 82: "It is certainly true that vocal music, performed by solo singers or by choruses, was also described as the most important and meaningful kind of music." Cf. Politico 268b4-

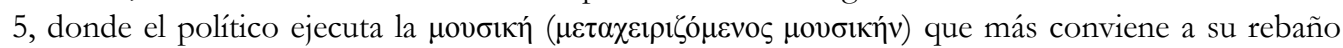

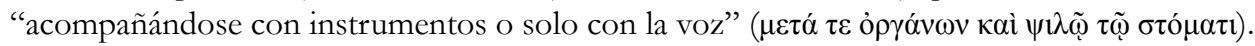

${ }^{39}$ Otro ejemplo tomado de las Leyes: los concursos musicales que se habrán de instaurar en la ciudad, divididos en monódicos y corales, incluyen entre los primeros certámenes no solo de citarodas, sino

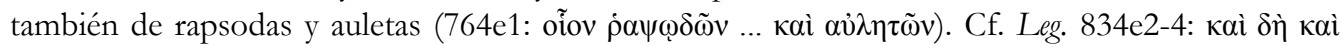
$\mu$

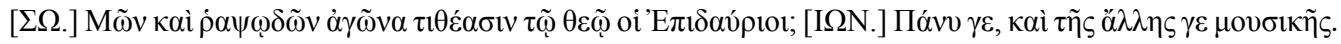
40 Esta es una cuestión que se ha planteado respecto al uso de $\mu$ ovбıќ́ en el libro VIII de la Política de Aristóteles. Según C. Lord (1982, p. 185-92) el uso incluye la poesía; a esta interpretación se opuso A. Ford (2004, p. 314-23), que considera que el uso es restringido a partir de Pol. VIII, 5.
} 


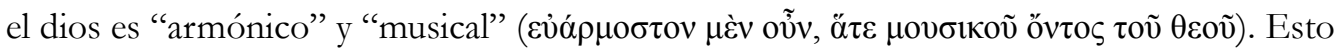

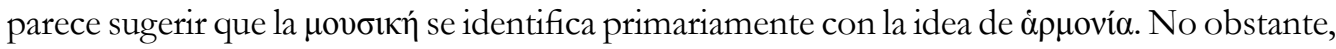
está claro que Sócrates piensa en la ápuovía musical como existiendo en la canción (405d1:

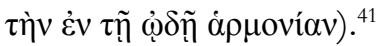

En el libro final de la República, donde se retoma el tema de la "expulsión de los poetas", se dice que estos imitan con "nombres y locuciones, a los que añaden colores

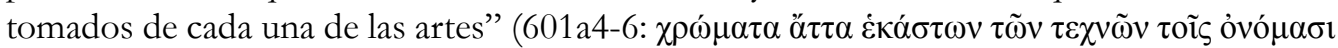

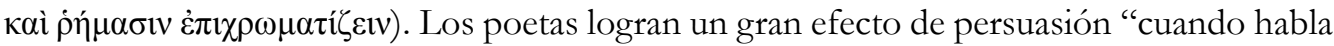

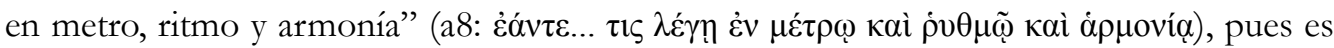
enorme el hechizo natural de estas cosas. Todo este hechizo, sin embargo, lo pierden "las

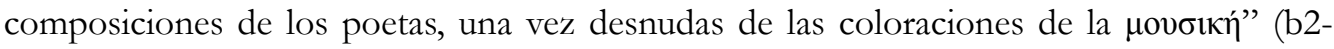

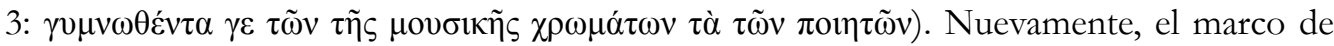
referencia es indudablemente la canción, con o sin acompañamiento instrumental -el pasaje, de hecho, sugiere que no hay instrumentación. Sin embargo, parece igualmente claro que hay una distinción entre lo poético y lo musical. Lo poético son "los nombres y las locuciones"

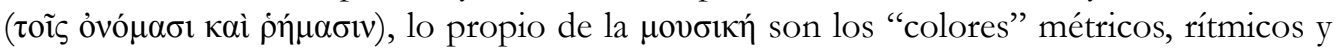
armónicos, la dimensión sonora de la canción. ${ }^{42}$

Existen, al mismo tiempo, casos donde probablemente se limite el ámbito del arte musical, con exclusión implícita de la $\lambda \varepsilon \varepsilon_{\xi}$ s. Se trata de contextos no paideúticos, sino teóricos. En Teetetos 206a10-b4, el músico es aquel que sabe identificar la altura de cada sonido ( $\tau \tilde{\omega}$

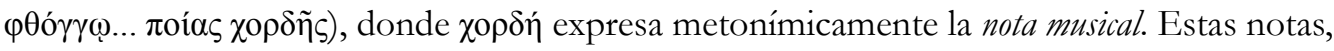

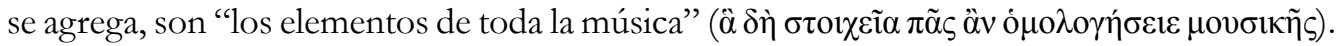
Esto, es verdad, sigue siendo inconclusivo. Más determinante es el Filebo, donde se habla de la música como de una ciencia. Primero se dice (17b6-e2) que el conocimiento completo de la

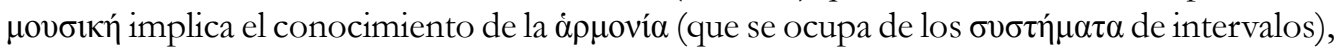

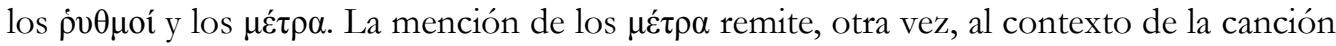
y de la música vocal, pero al mismo tiempo separa lo musical de la dicción poética, pues todos estos aspectos se dice que confluyen en algo común, el número, que está ausente de

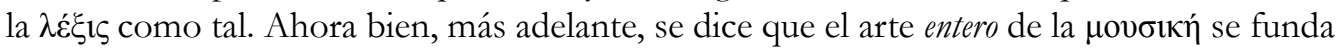

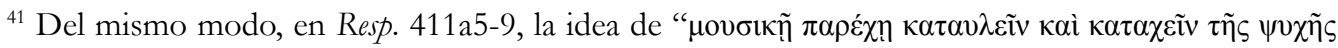
$\delta i \alpha ̀ ~ \tau \tilde{\omega} \nu \omega ̋ \tau \omega \nu$ ” parece privilegiar el aspecto sonoro por encima del lingüístico, pero aún aquí se está

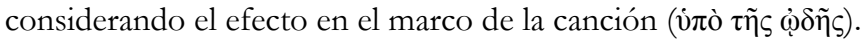

${ }^{42}$ Otro tanto ocurre con pasajes como aquel del Simposio donde se dice que la $\mu$ ovøı́n se ocupa

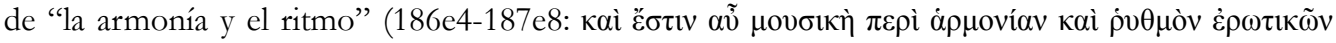

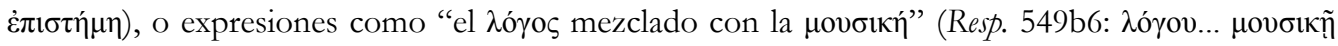

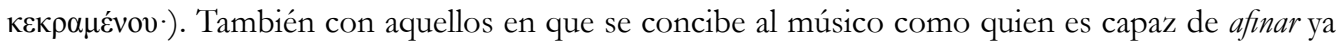

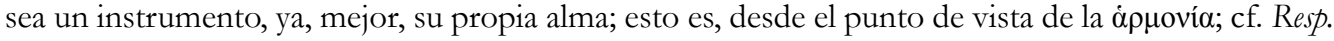

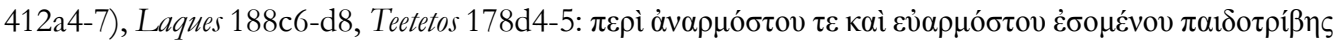

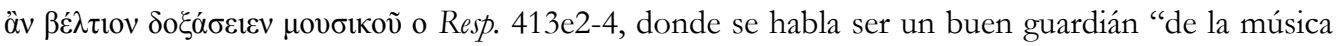

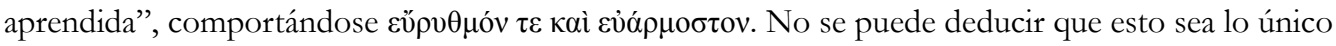
de que se ocupa el $\mu$ ovбıкós, aunque parece ser aquello que le concierne primariamente. 


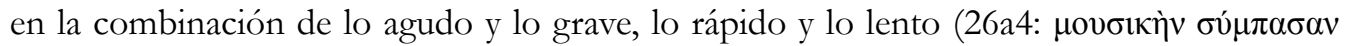

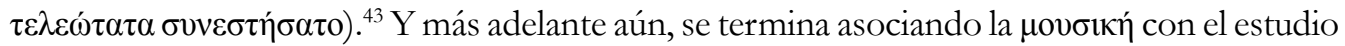
de las consonancias ( $\tau$ ò $\sigma u ́ \mu \varphi \omega v o v$ ), tomando como referencia para la actividad práctica del músico a la aulética, es decir, a la música instrumental (56a3-7). ${ }^{44}$

\section{VI}

No obstante, estos ejemplos de uso "restringido" son sin duda marginales en Platón. Persiste firme el hecho de que en los contextos donde se la trata desde el punto de vista

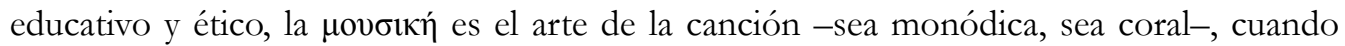
no el arte de la recitación. ${ }^{45}$ En un célebre pasaje de las Leyes (669b-e) este concepto se

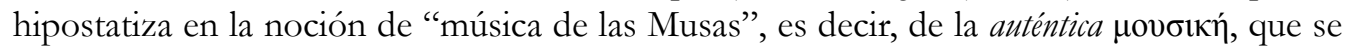

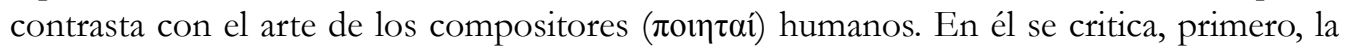
práctica de asociar palabras, melodías, ritmos y figuras de danza de diferente cualidad (libres con esclavas, masculinas con femeninas, etc.) y en segundo lugar, la práctica de disociar los

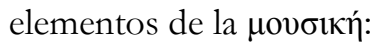

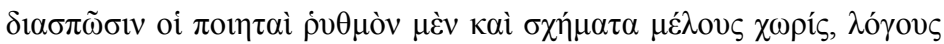

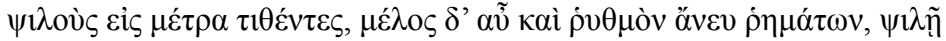

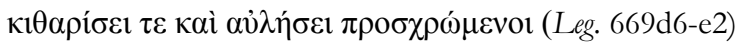

Los poetas [humanos] disocian el ritmo y las figuras de danza de las melodías, componiendo $\lambda$ ó $\gamma o$ desnudos con métrica, y a su vez, melodía y ritmo sin palabras, practicando la citarística y la aulética desnudas.

Las Musas, por el contrario, "nunca errarían a tal punto" (669c3). El pasaje es notable porque define el concepto de la verdadera música por oposición a la que considera la práctica musical no solo corriente, sino humana en general. Las consideraciones que lo motivan son, indudablemente, pedagógicas. Respecto a la práctica de mezclar elementos de cualidades opuestas, el problema general es que en función de las cualidades miméticas y éticas de los distintos elementos musicales, obras incongruentes respecto al carácter generarían en las almas caracteres incongruentes, que en última instancia no son caracteres en absoluto. Respecto a

\footnotetext{
${ }^{43}$ Cf. Sofista 253b1-4, donde el músico es quien sabe "respecto de los sonidos agudos y graves" ( $\pi \varepsilon \rho \grave{~}$

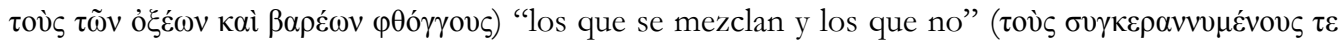

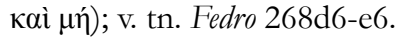

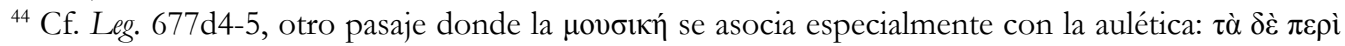

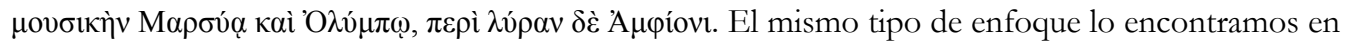
el libro VII de la República.

${ }^{45}$ Está claro que la $\mu$ ovбıќ́ que se propone en la Repúbica es siempre un arte compuesta, y que su

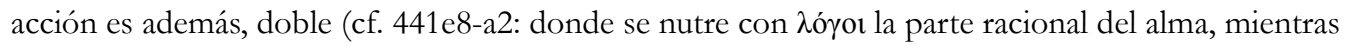

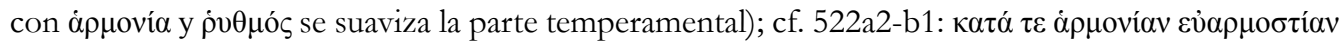

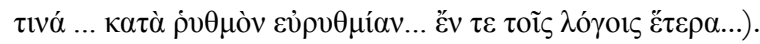


la práctica de la música instrumental, se señala la dificultad de reconocer qué quiere decir la

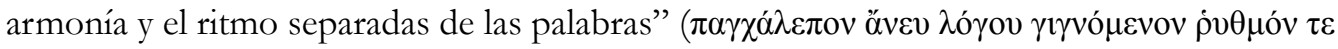

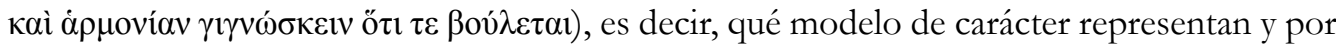
lo tanto qué modelo proyectan en las almas de la juventud. Al mismo tiempo, la dimensión musical de la palabra resulta imprescindible, debido al placer natural que los humanos sentimos por la armonía y el ritmo y al hecho de que la música cala en lo profundo del alma con una intensidad especial. En suma, se trata, como señala Eleonora Rocconi, de potenciar la capacidad mimética de la $\mu$ ovбıкń. ${ }^{46}$

En los ҮПM, como ya mencioné, se cita in extenso este pasaje de las Leyes. Aquí resulta pertinente la diferencia entre los modelos editoriales de los YПM que señalábamos antes (supra §III). En el modelo de Kemke este pasaje correspondería al libro I, dedicado, supuestamente, a la filosofía musical de Platón. En la nueva reconstrucción bibliológica de Delattre, sin embargo, cae hacia el final del resumen del libro IV, por lo cual más bien habría que conectarlo con Diógenes de Babilonia, o al menos con la filosofía musical de los estoicos, antes que directamente con Platón.

Delattre dedicó un artículo entero al asunto. En él reconoce, por una parte, la imposibilidad de determinar concluyentemente a partir de los datos textuales si la cita pertenece a Diógenes o a Filodemo. ${ }^{47} \mathrm{Al}$ mismo tiempo, considera más probable que estuviera incluida en el supuesto tratado Sobre la música de Diógenes, pues ¿por qué Filodemo habría de citar a Platón en un libro dedicado a criticar las posiciones estoicas? ${ }^{48} \mathrm{Y}$ además, ¿¿por qué incluiría una cita para la que no parece haber ninguna réplica correspondiente en la parte crítica? ${ }^{49}$

Para finalizar, quisiera sugerir que, pace Delattre, existe efectivamente una tal correspondencia, a saber, entre la col. 51,12ss. y la col. 140,14ss., es decir, entre la cita de las

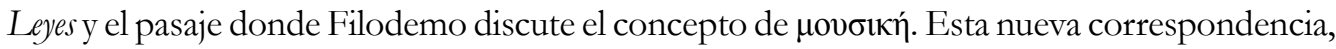
si se la aceptara, caería exactamente entre las correspondencias $n^{\circ} 30$ y n ${ }^{\circ} 31$, que es la última detectada por Delattre, existente entre col. 53, 8-9 y col. 142, 1-14, relativa a la mención de las ideas de Cleantes sobre la relación entre música y poesía. Sería, pues, la penultima de las correspondencias hasta ahora detectadas y admitidas. Reproduzco la parte final de la cita, cuyo texto los editores en gran medida han conjeturado a partir del locus paralelo de las Leyes:

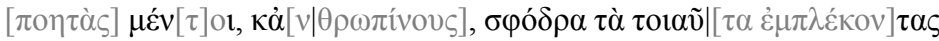

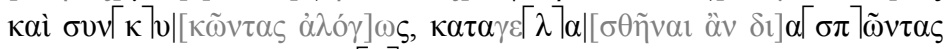

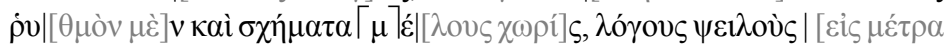

\footnotetext{
${ }^{46}$ Rocconi, 2016, p. 82: "The remarks [...] on the need, for all the elements of a musical composition to be consistent with one another, and to fit into a particular genre 'by law', are assertions intended to reinforce the representational power of music..."

${ }^{47}$ Delattre, 1991, p. 14: “Ensuite, il s’est révélé extrêmement délicat de décider, en s'appuyant sur des indices matériels solides, si c'est Diogène ou, un siècle plus tard, Philodème à qui l'on doit attribuer les modifications de cette longue 'citation' de Platon. En effet, bien souvent, on l'a vu, les indices peuvent être interprétés dans un sens comme dans l'autre."

${ }^{48}$ Delattre, 1991, p. 15.

${ }^{49}$ Ibid.: "il n'y a pas trace d'une réfutation explicite de cette page de Platon dans la fin du livre IV".
} 


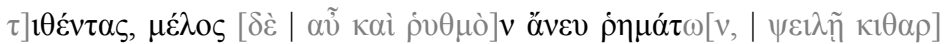

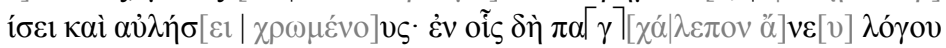

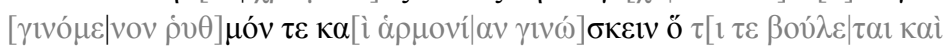

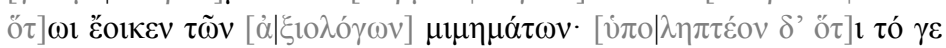

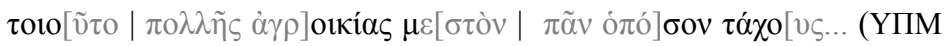
$51,32-47)$

Sin embargo, los poetas humanos, que a menudo entrelazan y combinan este tipo de cosas de forma irracional, resultan ridículos cuando disocian de la melodía el ritmo y las figuras de danza, o versifican palabras desnudas, y a su vez, ['componen] una melodía y un ritmo sin palabras, haciendo uso de la citarística y la aulética instrumentales. En todos estos casos, ciertamente, se vuelve muy difícil reconocer, sin el discurso, cuál es el significado del ritmo y la armonía, y a cuál de los modelos dignos de consideración se asemejan. Se ha de sobrentender, sin duda, que todo esto está lleno de abundante rusticidad, puesto que manifiesta un gusto por la rapidez...

Sugiero que Diógenes o, quizá mejor, los adversarios estoicos de Filodemo, acudían

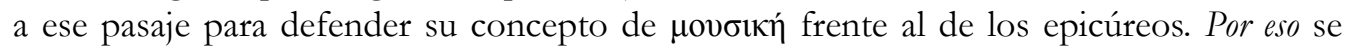
lo incluye en ese lugar del resumen. En el pasaje de Platón, nótese, se dice que la práctica

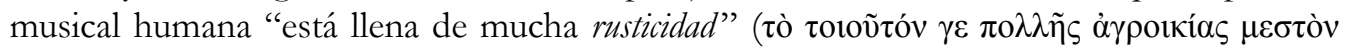
$\pi \tilde{\alpha} v)$. Posiblemente fuera a partir de este mismo texto platónico que los oponentes hacían extensiva a Filodemo la acusación de ảypoıkí $\alpha$. Filodemo, por lo demás, es explícito al señalar que el reproche de rusticidad se refiere específicamente a la definición epicúrea de $\mu$ ovбıкń y

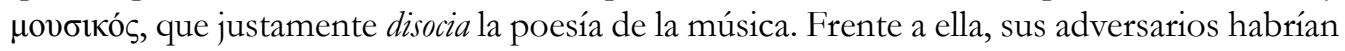
erigido la imagen platónica, y controversial, de la "música de las Musas", como expresión de su ideal músico-paidéutico. ${ }^{50}$

\section{REFERENCIAS}

ANNAS, Julia. Hellenistic philosophy of mind. Berkeley: University of California Press, 1994.

BARKER, Andrew. Diogenes of Babylon and Hellenistic musical theory. In AUVRAYASSAYAS, C.; DELATTRE, D. (ed.). Cicéron et Philodème: la polémique en philosophie. Paris: Rue d'Ulm, 2001, p. 353-370.

BARKER, Andrew. Greek musical writings II. Harmonic and acoustic theory. Cambridge: Cambridge University Press, 1989.

BOWMAN, Wayne. PhilosophicalPerspectives on Music. New York: Oxford University Press, 1998.

\footnotetext{
${ }^{50}$ Recuérdese que, según los estoicos, "se le llama Musas a la música y a todas las artes educativas"

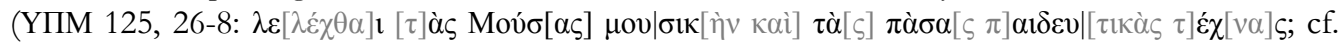
148, 29-33).
} 
DELATTRE, Daniel. Aperçus sur l'épicurisme de Philodème de Gadara. À propos du livre IV du De musica et de la distinction stoïcienne entre sensation naturelle et sensation savante. In LEVY, C. (ed.). Le concept de nature à Rome. La physique. Paris: Rue d’Ulm, 1996, p. 85-108.

DELATTRE, Daniel (ed.). Philodème de Gadara. Sur la musique, Livre IV. Paris: Les Belles Lettres, 2007. 2 v. (Collection de Universités de France).

DELATTRE, Daniel. Une 'citation' stoïcienne des Lois (II, 669 B-E) de Platon dans les Commentaires sur la musique de Philodème? Revue d’histoire des textes, n. 21, p. 1-17, 1991.

DORANDI, Tiziano. La 'Villa Dei Papiri' a Ercolano e la sua biblioteca. Classical Philology, v. 90, n. 2, p. 168-182, 1995.

FERRARIO, Matilde. Parola e musica in 'Plutarco' en Filodemo. Quaderni Urbinati di Cultura Classica, v. 99, n. 3, p. 73-82, 2011.

FORD, Andrew. Catharsis: the power of music in Aristotle's Politics. In MURRAY, Penelope; WILSON, Peter (ed.). Music and the Muses. The culture of 'mousike' in the Classical Athenian city. Oxford: Oxford University Press, 2004, p. 309-336.

KEMKE, Ioannes (ed.). Philodemi de musica librorum quae exstant. Leipzig: Teubner, 1884.

LONGO AURICCHIO, Francesca; INDELLI, Giovanni; LEONE, Giuliana; DEL MASTRO, Gianluca. La Villa dei Papiri. Una residenza antica e la sua biblioteca. Roma: Carocci editore, 2020.

LORD, Carnes. Education and culture in the political thought of Aristotle. Ithaca: Cornell University Press, 1982.

MONTANA, Fausto. Hellenistic Scholarship. In MONTANARI, F.; MATTHAIOS, S.; RENGAKOS, A. Brill's companion to Ancient Greek scholarship. Leiden: Brill, 2015. v. 1, p. 60-183.

MURRAY, Penelope; WILSON, Peter (ed.). Music and the Muses. The culture of 'mousike' in the Classical Athenian city. Oxford: Oxford University Press, 2004.

NEUBECKER, Annemarie (ed.). Philodemus. Über die Musik iv. Buch. Napoli: Bibliopolis, 1986.

ROCCONI, Eleonora. The music of the Laws and the laws of music: nomo $i$ in music and legislation. Greek and Roman musical studies, v. 4, p. 71-89, 2016.

ROCCONI, Eleonora. Music and dance in Greece and Rome. In DESTRÉE, P.; MURRAY, P. A companion to ancient aesthetics. Wiley Blackwell: 2015, p. 81-93.

SIDER, David. The Library of the Villa dei Papiri at Herculaneum. Los Angeles: J. Paul Getty Museum, 2005.

TSOUNA, Voula. The ethics of Philodemus. Oxford: Oxford University Press, 2007. 